OPEN ACCESS

Edited by:

Eugenia Bezirtzoglou,

Democritus University of Thrace,

Greece

Reviewed by:

Karola Böhme

University of Santiago

de Compostela, Spain

Victoria Girard,

bioMérieux, France

Jaroslav Hrabak,

Charles University, Czechia

${ }^{*}$ Correspondence:

Duochun Wang

wangduochun@icdc.cn

Specialty section:

This article was submitted to

Food Microbiology,

a section of the journal

Frontiers in Microbiology

Received: 13 November 2020

Accepted: 04 January 2021

Published: 18 February 2021

Citation:

Yu K, Huang Z, Li Y, Fu Q, Lin L, Wu S, Dai H, Cai H, Xiao Y, Lan R and

Wang D (2021) Establishment and Application of Matrix-Assisted

Laser Desorption/lonization Time-of-Flight Mass Spectrometry for Detection of Shewanella Genus.

Front. Microbiol. 12:625821. doi: 10.3389/fmicb.2021.625821

\section{Establishment and Application of Matrix-Assisted Laser Desorption/Ionization Time-of-Flight Mass Spectrometry for Detection of Shewanella Genus}

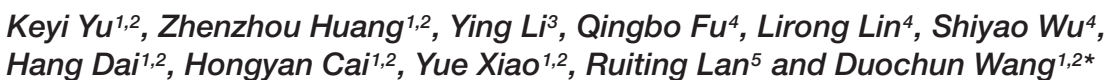

\footnotetext{
${ }^{1}$ National Institute for Communicable Disease Control and Prevention, Chinese Center for Disease Control and Prevention (China CDC), State Key Laboratory for Infectious Disease Prevention and Control, Beijing, China, ${ }^{2}$ Center for Human Pathogenic Culture Collection, China CDC, Beijing, China, ${ }^{3}$ Workstation for Microbial Infectious Disease, Shunyi District Center for Disease Control and Prevention, Beijing, China, ${ }^{4}$ Zybio Inc., Chongqing, China, ${ }^{5}$ School of Biotechnology and Biomolecular Sciences, University of New South Wales, Sydney, NSW, Australia
}

Shewanella species are widely distributed in the aquatic environment and aquatic organisms. They are opportunistic human pathogens with increasing clinical infections reported in recent years. However, there is a lack of a rapid and accurate method to identify Shewanella species. We evaluated here matrix-assisted laser desorption/ionization time-of-flight mass spectrometry (MALDI-TOF MS) for rapid identification of Shewanella. A peptide mass reference spectra (PMRS) database was constructed for the type strains of 36 Shewanella species. The main spectrum projection (MSP) cluster dendrogram showed that the type strains of Shewanella species can be effectively distinguished according to the different MS fingerprinting. The PMRS database was validated using 125 Shewanella test strains isolated from various sources and periods; $92.8 \%(n=116)$ of the strains were correctly identified at the species level, compared with the results of multilocus sequence analysis (MLSA), which was previously shown to be a method for identifying Shewanella at the species level. The misidentified strains $(n=9)$ by MALDI-TOF MS involved five species of two groups, i.e., Shewanella algae-Shewanella chilikensis-Shewanella indica and Shewanella seohaensis-Shewanella xiamenensis. We then identified and defined species-specific biomarker peaks of the 36 species using the type strains and validated these selected biomarkers using 125 test strains. Our study demonstrated that MALDITOF MS was a reliable and powerful tool for the rapid identification of Shewanella strains at the species level.

Keywords: MALDI-TOF mass spectrometry, detection, Shewanella, multilocus sequence analysis, establishment and application 


\section{INTRODUCTION}

The genus Shewanella comprises a group of oxidase-, catalase-, and ornithine decarboxylase-positive and $\mathrm{H}_{2} \mathrm{~S}$-producing, facultative anaerobic bacteria with a wide distribution in the environment. It plays an important ecological role in many fields such as materials engineering, environmental engineering (Zou et al., 2018), and marine biology (Gorby et al., 2006; Fredrickson et al., 2008; Kouzuma et al., 2015; Daeffler et al., 2017). However, Shewanella is a common source of food spoilage bacteria, in particular seafood; and Shewanella contamination of foods during food processing and storage adversely affects the production, transportation, and sales (Hau and Gralnick, 2007; McLean et al., 2008; Wang et al., 2009; Janda and Abbott, 2014). Shewanella is also an opportunistic pathogen of humans (Erfanmanesh et al., 2019). Through occupational or recreational activities, exposure to the marine environment containing Shewanella or ingestion of marine organisms contaminated by Shewanella (Janda and Abbott, 2014) may cause a range of infections including skin and soft tissue infections (SSTIs), invasive diseases, hepatobiliary diseases, otitis media and associated sequelae, and other infections (Janda and Abbott, 2014). Some studies have shown that SSTI is the most common clinical features of Shewanella infection, including cellulitis, abscess, or necrotizing fasciitis (Yousfi et al., 2017). In recent years, Shewanella has been isolated from more and more clinical specimens (Janda and Abbott, 2014).

The genus of Shewanella has a high diversity with more than 70 species reported so far ${ }^{1}$. An efficient and accurate method for the identification of Shewanella species is still lacking. Traditional methods are mainly based on phenotypic tests combined with biochemical identification, which is time-consuming, laborious, and even inaccurate. The widely used 16S rRNA gene as bacterial species identification tool (Yarza et al., 2014) has been found to lack the power to identify Shewanella at the species level (Sun et al., 2013; Glaeser and Kämpfer, 2015). The housekeeping gene gyrB was found to have a higher resolution than 16S rRNA for Shewanella species identification (Bozal et al., 2002; Miyazaki et al., 2006; Sung et al., 2012), but no standardized cutoff value has been established for the identification (Bozal et al., 2002; Miyazaki et al., 2006; Sung et al., 2012). We previously established that the method of multilocus sequence analysis (MLSA) can accurately identify Shewanella at the species level (Fang et al., 2019). This method requires PCR and sequencing of six housekeeping genes from each isolate, which is time-consuming and costly. Thus, the method is unsuitable for clinical diagnostic laboratories.

Matrix-assisted laser desorption/ionization time-of-flight mass spectrometry (MALDI-TOF MS) has become a powerful technology for rapid microbial identification in recent years. It has a short turnaround time for species identification to enable targeted treatment. The principle of MALDI-TOF MS based on species identification is that each species has its characteristic MS spectra that provide a good resolution for differentiation of bacteria at the species level (van Belkum et al., 2015). MALDI-TOF MS has been rapidly developed and widely used in

${ }^{1}$ http://www.bacterio.net/shewanella.html clinical laboratories (Angeletti, 2017; Schubert and Kostrzewa, 2017), due to its advantages of convenient sample preparation, simple experimental operation, and high identification accuracy (Samantha et al., 2018). A key requirement of MALDI-TOF MS based on species identification is a specific and accurate spectra database (Jang and Kim, 2018), which must be established for the targeted species.

The objectives of this study were to establish a peptide mass reference spectra (PMRS) database of Shewanella species by MALDI-TOF MS and to validate the effectiveness of MALDITOF MS and the database for identifying Shewanella species, using type strains of 36 species and 125 test strains derived from clinical, environmental, and food samples.

\section{MATERIALS AND METHODS}

\section{Bacterial Strains and Cultivation Methods}

A total of 161 Shewanella strains were used in this study including 36 type strains and 125 test strains. All type strains were sourced from the China General Microbiological Culture Collection Center (CGMCC), the German Collection of Microorganisms and Cell Cultures [Deutsche Sammlung von Mikroorganismen und Zellkulturen (DSMZ)], the Japan Collection of Microorganisms (JCM), the Korean Collection for Type Cultures (KCTC), the Belgian Co-ordinated Collections of Micro-organisms (BCCM/LMG Bacteria Collection), and the Marine Culture Collection of China (MCCC). Detailed information of type strains is listed in Table 1. The three non-Shewanella strains, namely, Vibrio cholerae N16961, Pseudomonas aeruginosa 09MAS0023, and Aeromonas hydrophila 2247, were sourced from Center for Human Pathogenic Culture Collection (CHPC). The test strains were isolated from different sources in China, during years 2007-2020, including clinical $(n=75)$, food $(n=39)$, and environmental $(n=11)$ isolates. The 36 Shewanella type strains were incubated on marine agar $2216 \mathrm{E}$ at suitable temperatures according to the protocols provided by each pathogen culture collection center. The test strains were identified by API20E (bioMérieux SA) according to instrument of manufactory and incubated at $37^{\circ} \mathrm{C}$ for 18-24 h for subsequent identifications. Escherichia coli ATCC 25922 was used for the calibration of the instrument.

\section{Sample Preparation for Matrix-Assisted Laser Desorption/lonization Time-of-Flight MS}

An ethanol/formic acid method was used for protein extraction (Anja and Sascha, 2009). One loop of fresh bacterial culture was thoroughly suspended in $300 \mu \mathrm{l}$ of ultrapure water, and then $900 \mu \mathrm{l}$ of absolute ethanol was added. The mixtures were centrifuged at $14,000 \times g$ for $5 \mathrm{~min}$. Then the supernatant was discarded, and the pellet was allowed to dry at room temperature. Next, equal volumes of $70 \%$ formic acid and acetonitrile were added to the pellet in sequence. After the pellet was well suspended, it was centrifuged at $14,000 \times g$ 
TABLE 1 | Detailed information of 36 Shewanella type strains.

\begin{tabular}{|c|c|c|c|c|c|}
\hline No. & Species & Strain & Isolation place & Isolation source & Isolation year\# \\
\hline 1 & Shewanella aestuarii & $\mathrm{JCM} 17801^{\top}$ & Suncheon Bay, Korea & A tidal flat & 2011 \\
\hline 2 & Shewanella algae & $\mathrm{JCM} 21037^{\top}$ & Japan & Red alga & 1990 \\
\hline 3 & Shewanella algicola & KCTC $23253^{\top}$ & Jeju Island, Korea & Brown alga, Sargassum thunbergii & - \\
\hline 4 & Shewanella algidipiscicola & LMG $23746^{\top}$ & Baltic Sea, Denmark & Plaice & 2001 \\
\hline 5 & Shewanella aquimarina & $\mathrm{JCM} 12193^{\top}$ & Yellow Sea, Korea & Seawater & - \\
\hline 6 & Shewanella baltica & DSM $9439^{\top}$ & Japan & Oil brine & 1998 \\
\hline 7 & Shewanella basaltis & KCTC $22121^{\top}$ & Jeju Island, Korea & Marine black sand & - \\
\hline 8 & Shewanella carassii & 08MAS $2251^{\top}$ & Anhui, China & $\begin{array}{l}\text { Surface of crucian carp, Carassius } \\
\text { carassius }\end{array}$ & 2008 \\
\hline 9 & Shewanella chilikensis & KCTC $22540^{\top}$ & Orissa, India & Sediment of a lagoon & 2007 \\
\hline 10 & Shewanella corallii & DSM $21332^{\top}$ & Red Sea, Israel & A coral & 2005 \\
\hline 11 & Shewanella decolorationis & $\mathrm{JCM} 21555^{\top}$ & Guangzhou, China & Activated sludge & 2002 \\
\hline 12 & Shewanella dokdonensis & KCTC $22898^{\top}$ & East Sea, Korea & Seawater & 2006 \\
\hline 13 & Shewanella electrodiphila & DSM $24955^{\top}$ & Mid-Atlantic Ridge & Deep-sea sediment & 2007 \\
\hline 14 & Shewanella gaetbuli & KCTC $22431^{\top}$ & Korea & A tidal flat & - \\
\hline 15 & Shewanella gelidii & MCCC $1 \mathrm{~K} 00697^{\top}$ & Yellow Sea, China & Red alga, Gelidium amansii & 2014 \\
\hline 16 & Shewanella glacialipiscicola & LMG $23744^{\top}$ & Baltic Sea, Denmark & Cod & 1996 \\
\hline 17 & Shewanella hafniensis & KCTC $22180^{\top}$ & Baltic Sea, Denmark & Cod & 2001 \\
\hline 18 & Shewanella hanedai & DSM $6066^{\top}$ & Arctic Ocean & Marine sediment & - \\
\hline 19 & Shewanella indica & KCTC23171 ${ }^{\top}$ & Karwar jetty, India & Sediment of the Arabian Sea & 2006 \\
\hline 20 & Shewanella inventionis & KCTC $42807^{\top}$ & Okinawa Trough & Deep-sea sediment & 2014 \\
\hline 21 & Shewanella kaireitica & DSM $17170^{\top}$ & Suruga Bay, Japan & Deep-sea sediment & - \\
\hline 22 & Shewanella litorisediminis & KCTC $23961^{\top}$ & Saemankum, Korea & A tidal flat sediment & - \\
\hline 23 & Shewanella livingstonensis & LMG $19866^{\top}$ & Johnson's Dock, Antarctica & Water & - \\
\hline 24 & Shewanella mangrovi & MCCC $1 \mathrm{~A} 00830^{\top}$ & Fujian, China & Mangrove sediment & 2013 \\
\hline 25 & Shewanella marinintestina & $\mathrm{JCM} 11558^{\top}$ & Yokohama, Japan & Squid body & 1994 \\
\hline 26 & Shewanella marisflavi & $\mathrm{JCM} 12192^{\top}$ & Yellow Sea, Korea & Seawater & - \\
\hline 27 & Shewanella olleyana & LMG $21437^{\top}$ & Tasmania, Australia & Saline waters of estuary & 1998 \\
\hline 28 & Shewanella pacifica & KCTC $12235^{\top}$ & Chazhma Bay, Japan & Seawater & - \\
\hline 29 & Shewanella pneumatophori & KCTC $23973^{\top}$ & Japan & $\begin{array}{l}\text { The intestines of Pacific mackerel, } \\
\text { Pneumatophorus japonicus }\end{array}$ & 1987 \\
\hline 30 & Shewanella profunda & $\mathrm{JCM} 12080^{\top}$ & Pacific Ocean & Deep marine sediment & 2000 \\
\hline 31 & Shewanella putrefaciens & ATCC $8071^{\top}$ & England & Butter & 1931 \\
\hline 32 & Shewanella sairae & MCCC $1 \mathrm{~A} 01705^{\top}$ & Pacific Ocean & Saury intestine & 1995 \\
\hline 33 & Shewanella schlegeliana & $\mathrm{JCM} 11561^{\top}$ & Hiroshima, Japan & Black porgy intestine & 1998 \\
\hline 34 & Shewanella seohaensis & KCTC $23556^{\top}$ & Saemankum, Korea & A tidal flat sediment & - \\
\hline 35 & Shewanella vesiculosa & LMG $24424^{\top}$ & Deception Island & Marine sediments & - \\
\hline 36 & Shewanella xiamenensis & MCCC 1A00763 ${ }^{\top}$ & Fujian, China & Coastal sea sediment & - \\
\hline
\end{tabular}

\# "-" means isolation year unknown.

for $3 \mathrm{~min}$, and the whole cell extracts were transferred to a clean tube. The matrix solution consisted of acetonitrile $(500 \mu \mathrm{l})$, ultrapure water $(475 \mu \mathrm{l})$, trifluoroacetic acid $(25 \mu \mathrm{l})$, and supersaturated $\alpha$-cyano-4-hydroxycinnamic acid (CHCA) (Zybio Inc., Chongqing, China). One microliter of the protein extracts was spotted onto a 96-well target plate (Zybio Inc., Chongqing, China). Each spot was overlaid with $1 \mu \mathrm{l}$ of matrix solution and allowed to dry at room temperature.

\section{Parameter Setting, Spectrum Generation, and Identification}

Mass spectrometry analysis was performed using MALDI-TOF MS EXS3000 (Zybio Inc., Chongqing, China). MS spectra were obtained in linear mode within a range of 2,000-20,000 Da. E. coli ATCC 25922 was used for mass calibration and instrument parameter optimization, to make the average deviation of molecular weight less than $300 \mathrm{ppm}$ after correction. MS data were analyzed by MDT Master (version 1.1). As specified by the manufacturer's instructions, log scores $\geq 2.0$ were accepted for the identification at the species level, and log scores $<2.0$ and $\geq 1.7$ were taken as the identification at the genus level or the presumptive species level identification. Log scores below 1.7 were considered unreliable.

Each sample was coated with 12 targets. At least 24 highquality spectra with stable baseline, abundant protein peaks and even distribution were selected. The software of iDBac (version 1.1.10) was used to create the dendrogram based on the main 


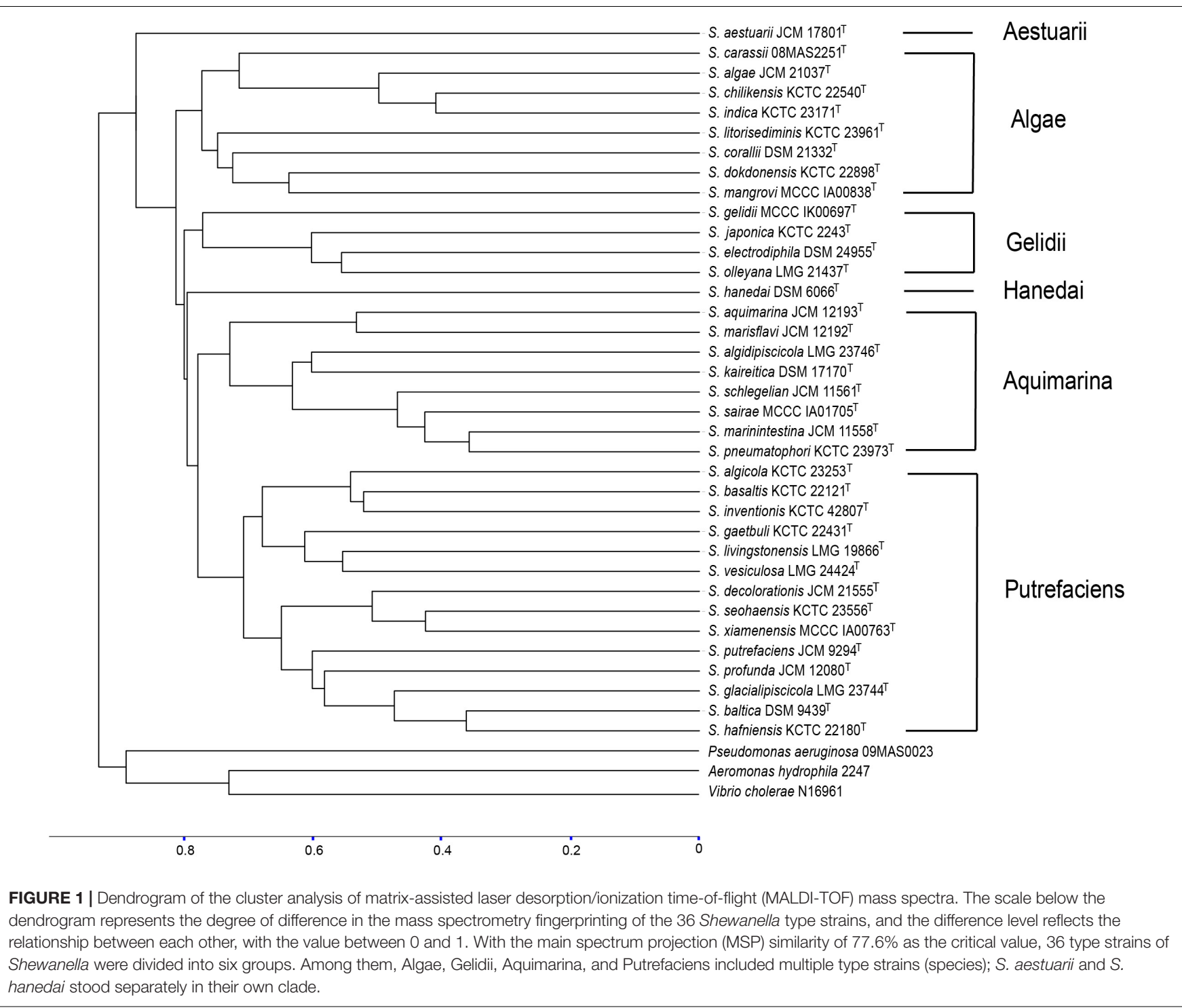

spectrum projection (MSP), using the algorithm of unweighted pair-group method with arithmetic means (UPGMA). Three non-Shewanella strains were included as controls.

\section{Multilocus Sequence Analysis of Shewanella Test Strains}

Genomic DNAs were extracted according to the standardized instructions of the DNA extraction kit (TaKaRa, Dalian, China). Six single-copy housekeeping genes (gyrA, gyrB, infB, recN, rpoA, and topA) were selected according to previous studies (Fang et al., 2019). Housekeeping genes of the 36 type strains were obtained from GenBank (Supplementary Table 1). DNAStar software was used to join the upstream and downstream sequences. MEGA 6.06 was used to compare the concatenated sequences and build the neighbor-joining phylogenetic tree. In terms of parameter setting of the evolutionary tree, Kimura's twoparameter model with the pairwise-deletion option was used. The robustness of tree topologies was evaluated with 1,000 bootstrap replications, and values $>70 \%$ were shown at the nodes of the branches.

\section{Analysis of Specific Biomarker Peaks in Mass Spectrometry}

Mass spectrometry analysis was performed using the MDT Master software to calculate the height and area of spectrum peaks, and Welch's $t$ test was used to determine peaks with statistical differences. Finally, an output file was generated. The peaks with relative signal intensity greater than $2 \%$ were extracted, and normality test ( $W$ test) was performed on the distribution of the peaks. Next, Kruskal-Wallis $H$ test (when $P$ value $<0.1$ in the $W$ test) was used to test pairwise difference of the peak distribution between strains. In all cases, $P$-value $<0.05$ was considered significant. The spectra peaks from different type strains were collected together, and non-redundant candidate species-specific biomarker peaks were computed for the 36 Shewanella species using MDT Master software. 


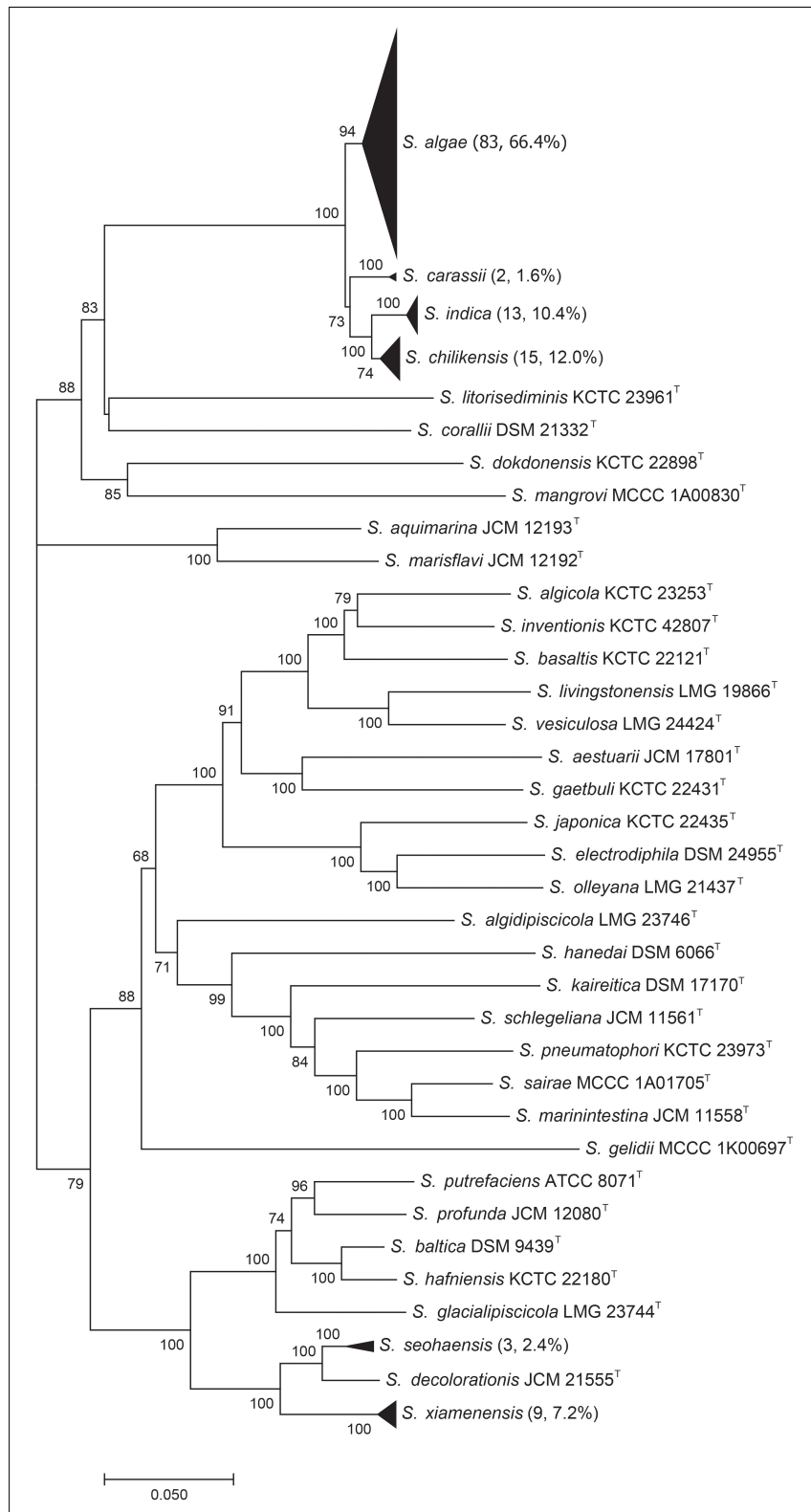

FIGURE 2 | Phylogenetic tree constructed based on six concatenated gene sequences [gyrA, gyrB, infB, recN, rpoA, and topA (4,191 bp)] of 36 Shewanella type strains and 125 test strains (by the neighbor-joining method). Each black triangle contains the test strains of the same species, and the number of test strains is shown in brackets. Numbers on branches are bootstrap values in percentage from 1000 replicates.

\section{RESULTS}

\section{Construction of Matrix-Assisted Laser Desorption/lonization Time-of-Flight MS Database for Shewanella Genus}

In this study, the PMRS database containing 36 type strains of different Shewanella species was constructed. About 100 peaks were detected in the MS fingerprinting of each strain, where

a large majority of the peaks were concentrated in the range of 3,000-10,000 $\mathrm{m} / \mathrm{z}$. The dendrogram based on MSP of 36 Shewanella showed long terminal branches that separate species from the nearest counterparts (Figure 1), and the variance of peaks distribution between branches ranged from 33.9\% (S. marinintestina-S. pneumatophore) to $84.5 \%$ (S. aestuarii). As the only genus in the family of Shewanellaceae, there was large difference in spectra between Shewanella and its closely related genera, which were considered as outgroups. No misidentification was observed at the genus level. The 36 type strains of different Shewanella species were divided into six clades, using the $77.6 \%$ difference in MSP as the cutoff value. The clade of Algae, Gelidii, Aquimarina, and Putrefaciens included multiple species, while $S$. aestuarii and $S$. hanedai were well separated as single species clades from the other clades.

\section{Species Identification of Test Strains by Multilocus Sequence Analysis}

Multilocus sequence analysis was used to provide a reference identification of all test strains. The concatenated sequences data were used to construct a phylogenetic tree (Figure 2). The test strains were clustered with type strains for unambiguous species identification. Among the 125 strains, 83 (66.4\%) were S. algae, 15 (12.0\%) S. chilikensis, 13 (10.4\%) S. indica, 9 (7.2\%) S. xiamenensis, 3 (2.4\%) S. seohaensis, and 2 (1.6\%) S. carassii. Except for $S$. seohaensis with all isolates from environmental specimens, the other five species contained isolates from clinical samples.

\section{Species Identification of Test Strains by Matrix-Assisted Laser Desorption/Ionization Time-of-Flight MS}

Under the condition of signal-to-noise ratio $>3.0$, approximately 100 peaks were detected in the range of $2,000-20,000 \mathrm{~m} / z$. When identifying the test strains, online comparison searches were performed against an expanded database (Zybio Inc., Chongqing, China, containing the Shewanella PMRS database). The final MALDI-TOF MS identification results for the 125 test strains were S. algae $(n=87)$, followed by S. chilikensis $(n=14)$, S. indica $(n=10)$, S. xiamenensis $(n=8)$, S. seohaensis $(n=4)$, and S. carassii $(n=2)$.

\section{Comparison of Results Between Multilocus Sequence Analysis and Matrix-Assisted Laser \\ Desorption/lonization Time-of-Flight MS}

Since MLSA has been confirmed to be accurate for identifying Shewanella at the species level (Fang et al., 2019), all 125 test strains were analyzed by MLSA, and the results were used to evaluate the effectiveness of MALDI-TOF MS for species identification. Taking the MLSA identification results as the "true species identity" of a test strain, all strains were identified correctly at the genus level, and 116 (92.8\%) of the test strains were accurately identified at the species level. Nine strains were misidentified by MALDI-TOF MS, involving five 


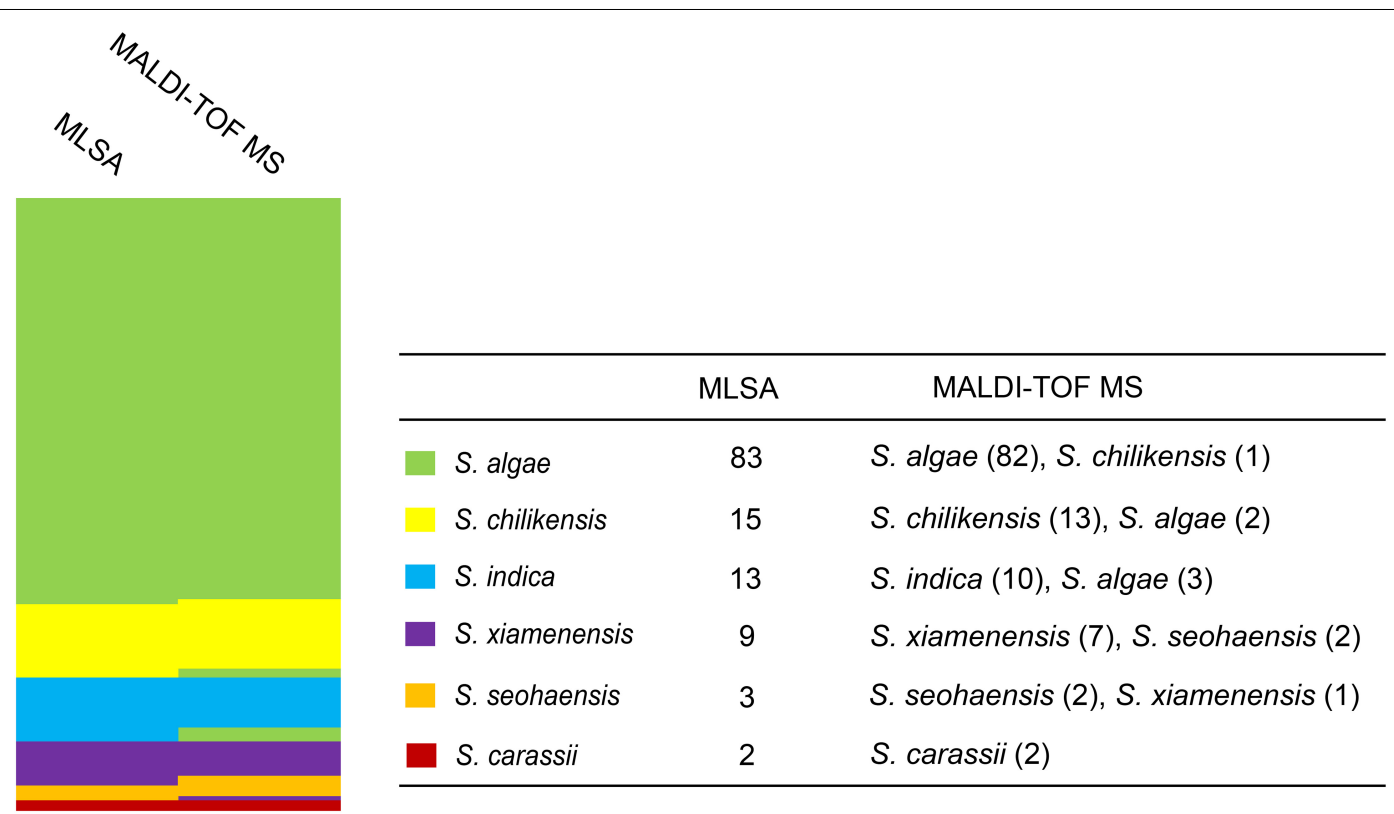

FIGURE 3 | Comparison of identification between multilocus sequence analysis (MLSA) and matrix-assisted laser desorption/ionization time-of-flight mass spectrometry (MALDI-TOF MS) for 125 test strains. Different colors represent different Shewanella species.

species of two groups, i.e., S. algae-S. chilikensis-S. indica and S. seohaensis-S. xiamenensis. More specifically, one S. algae strain was misidentified as $S$. chilikensis, while the two $S$. chilikensis strains and the three $S$. indica strains were wrongly identified as $S$. algae; two strains of $S$. xiamenensis were misidentified as $S$. seohaensis, and one strain of S. seohaensis was wrongly identified as S. xiamenensis (Figure 3).

\section{Analysis of Potential Species-Specific Biomarker Peaks}

Due to the misidentification of nine strains by MALDITOF MS, we analyzed the spectra data of the type strains to determine whether there are potential species-specific biomarker peaks that can be used to improve the accuracy. The output file of peak intensity for different type strains was generated by MDT Master Software. After the mass spectrum peaks with relative intensity $<2 \%$ were removed, the remaining peaks were collected for further analysis. Owing to the non-normal data, $P<0.05$ (Kruskal-Wallis $H$ test) was considered significant in peak distribution. Biomarker peaks were detected using peak lists among 36 type strains (Table 2), and 125 test strains were examined for verification. The potential species-specific biomarker peaks were located within the range of $2,000-12,000 \mathrm{~m} / z$. The nine wrongly identified strains were correctly identified at the species level by using the biomarker peaks. An average of eight speciesspecific peaks was found for each type strain, while $S$. aestuarii JCM $17801^{\mathrm{T}}$ harbored 21 specific peaks, higher than the average amount. Furthermore, S. aestuarii, S. aquimarina, S. baltica, S. carassii, and S. gaetbuli type strains harbored multiple specific peaks in a relative-low range $(2,000-3,000 \mathrm{~m} / z)$.
In the comparison of MS fingerprinting among $S$. algaeS. chilikensis-S. indica, the specific peaks were $10,065 \mathrm{~m} / z$ (S. algae), 3,307 m/z (S. chilikensis), and 4,827 $\mathrm{m} / \mathrm{z}$ (S. indica) (Figure 4A). Similarly, for the S. xiamenensis-S. seohaensis group, the peak with $4,221 \mathrm{~m} / z$ only appeared in $S$. xiamenensis, while peaks of $3,778 \mathrm{~m} / z$ and $9,574 \mathrm{~m} / z$ were present in S. seohaensis (Figure 4B).

\section{DISCUSSION}

Multiple Shewanella species are frequently isolated from food products and clinical specimens as opportunistic pathogens (Pagani et al., 2003; Liu et al., 2013; Janda and Abbott, 2014). Commercial systems, such as Vitek and MALDI-TOF MS (bioMérieux, Bruker), are available for species identification in clinical laboratories (Regoui et al., 2020; Sánchez-Juanes et al., 2020). However, only a few species, like S. putrefaciens and S. algae, were recorded in the database (Liu et al., 2013; Janda and Abbott, 2014; Zhang et al., 2018). Several other Shewanella species have often been misidentified by biochemical tests or MALDITOF MS (Byun et al., 2017; Zhang et al., 2018). Therefore, we urgently need an expanded database to identify Shewanella species correctly.

MALDI-TOF MS has revolutionized the routine identification of microorganisms in clinical laboratories by introducing a simple, rapid, high-throughput, and low-cost technology (O'Connor et al., 2016; Bao et al., 2018). The two key requirements of MALDI-TOF MS microbial identification are the species coverage in the database and the representativeness of bacterial diversity used for the database construction (RodriguezTemporal et al., 2017; Honnavar et al., 2018; Paul et al., 2019). 
TABLE 2 | Species-specific biomarker peaks of 36 Shewanella type strains.

\begin{tabular}{|c|c|c|c|}
\hline No. & Species & Strain & Species-specific biomarker peaks \\
\hline 1 & Shewanella aestuarii & $\mathrm{JCM} 17801^{\top}$ & $\begin{array}{l}2,784,2,956,2,970,3,874,3,882,4,323,4,345,4,915,5,209,5,230,5,913,6,816,6,827,6,838 \\
7,751,7,762,7,769,9,810,9,831,9,851,10,459\end{array}$ \\
\hline 2 & Shewanella algae & $\mathrm{JCM} 21037^{\top}$ & $4,654,4,661,5,086,5,347,6,163,6,231,6,534,8,641,10,065$ \\
\hline 3 & Shewanella algicola & KCTC $23253^{\top}$ & $2,816,3,793,5,309,5,663,8,999,9,196,9,452,9,932,11,344$ \\
\hline 4 & Shewanella algidipiscicola & LMG $23746^{\top}$ & $4,445,4,531,4,635,4,834,4,843,5,109,6,658,7,309,9,043$ \\
\hline 5 & Shewanella aquimarina & $J C M 12193^{\top}$ & $3,854,7,710,8,582$ \\
\hline 6 & Shewanella baltica & DSM $9439^{\top}$ & $2,700,4,061,5,443,6,307,7,564,8,409,10,887,10,887$ \\
\hline 7 & Shewanella basaltis & KCTC $22121^{\top}$ & $3,495,3,602,4,288,4,518,6,363,6,656,6,747,11,044$ \\
\hline 8 & Shewanella carassii & 08MAS2251 & $2,681,2,706,2,710,2,859,2,948,4,018,6,823,8,952,11,264$ \\
\hline 9 & Shewanella chilikensis & KCTC $22540^{\top}$ & $3,307,4,034,4,775,4,781,4,984,6,028,7,279,7,316,8,585,9,525,9,970$ \\
\hline 10 & Shewanella corallii & DSM $21332^{\top}$ & $2,290,2,614,2,906,3,615,4,849,5,478,7,216,7,232,8,742,9,699,10,957$ \\
\hline 11 & Shewanella decolorationis & $\mathrm{JCM} 21555^{\top}$ & $4,924,6,357,7,613,8,460,9,112,10,652,10,795$ \\
\hline 12 & Shewanella dokdonensis & KCTC $22898^{\top}$ & $3,644,3,808,4,319,4,846,5,064,5,083,5,369,6,132,7,619,10,146,10,319$ \\
\hline 13 & Shewanella electrodiphila & DSM $24955^{\top}$ & $2,238,6,916,7,409,8,593,9,156,9,279,9,325,11,135$ \\
\hline 14 & Shewanella gaetbuli & KCTC $22431^{\top}$ & $2,171,2,865,5,285,6,311,6,541,7,601$ \\
\hline 15 & Shewanella gelidii & MCCC $1 \mathrm{~K} 00697^{\top}$ & $4,384,4,957,5,547,5,602,5,990,9,926,9,941,9,957$ \\
\hline 16 & Shewanella glacialipiscicola & LMG $23744^{\top}$ & $3,367,4,625,6,790,11,193$ \\
\hline 17 & Shewanella hafniensis & KCTC $22180^{\top}$ & $3,552,4,855,5,495,5,892,7,343,8,413$ \\
\hline 18 & Shewanella hanedai & DSM $6066^{\top}$ & $3,937,4,858,7,300,7,442,7,469,9,715,10,243$ \\
\hline 19 & Shewanella indica & KCTC $23171^{\top}$ & $2,693,2,717,2,805,3,425,3,461,4,148,4,827,6,557,9,066,9,482$ \\
\hline 20 & Shewanella inventionis & КСTC $42807^{\top}$ & $5,674,5,997,8,172,11,230,11,303,11,319$ \\
\hline 21 & Shewanella kaireitica & DSM $17170^{\top}$ & $4,113,4,186,4,685,5,124,5,191,6,280,6,739,6,758,10,225$ \\
\hline 22 & Shewanella litorisediminis & KCTC $23961^{\top}$ & $2,552,2,713,3,034,3,886,3,909,4,496,4,651,5,483,6,435,6,626,10,965$ \\
\hline 23 & Shewanella livingstonensis & LMG $19866^{\top}$ & $3,819,4,805,7,639,9,974$ \\
\hline 24 & Shewanella mangrovi & MCCC $1 \mathrm{A00830}$ & $2,802,4,246,5,453,5,677,10,029,10,906,11,371$ \\
\hline 25 & Shewanella marinintestina & $\mathrm{JCM} 11558^{\top}$ & $3,458,4,550,6,224,6,336,7,429,7,569,9,060,9,263,10,388,11,169,11,176$ \\
\hline 26 & Shewanella marisflavi & $J C M 12192^{\top}$ & $3,527,3,555,5,469,6,053,6,204,7,306,9,239,10,237,10,937$ \\
\hline 27 & Shewanella olleyana & LMG $21437^{\top}$ & $2,174,2,329,6,695,7,530,9,057,9,143$ \\
\hline 28 & Shewanella pacifica & KCTC $12235^{\top}$ & $3,500,11,274$ \\
\hline 29 & Shewanella pneumatophori & KCTC $23973^{\top}$ & $2,642,5,196,11,019,11,129,11,137,11,214,11,224$ \\
\hline 30 & Shewanella profunda & JCM $12080^{\top}$ & $3,737,4,104,5,149,5,329,7,477,8,956,8,977,10,070,10,858$ \\
\hline 31 & Shewanella putrefaciens & ATCC $8071^{\top}$ & $3,365,3,759,4,509,4,664,6,351,7,552,9,659,10,098,10,867$ \\
\hline 32 & Shewanella sairae & MCCC 1A01705 & $6,546,7,474,8,579,9,460,9,640,11,029,11,125$ \\
\hline 33 & Shewanella schlegeliana & $\mathrm{JCM} 11561^{\top}$ & $8,254,11,161$ \\
\hline 34 & Shewanella seohaensis & KCTC $23556^{\top}$ & $2,448,3,172,3,778,4,454,4,823,6,129,7,159,8,501,9,574$ \\
\hline 35 & Shewanella vesiculosa & LMG $24424^{\top}$ & $4,760,4,790,4,998,6,652,6,668,9,071$ \\
\hline 36 & Shewanella xiamenensis & MCCC 1A00763 & $3,371,3,610,3,658,4,221,5,417,8,443,10,089,10,834$ \\
\hline
\end{tabular}

In this study, the PMRS database included the type strains of 36 Shewanella species for MALDI-TOF MS identification at both genus and species levels. The MSP dendrogram was used to evaluate the distance and relationship of the type strains that represent the 36 Shewanella species. The tree topology confirmed that each species is well separated. The previously recognized clades, i.e., Algae, Gelidii, Aquimarina, and Putrefaciens, were also grouped together respectively as expected, confirming the spectra contained sufficient signal for species identification. The identification accuracy of the MALDI-TOF MS was validated using 125 test strains, the species identity of which were confirmed by MLSA. The 125 test strains analyzed belonged to six different species, namely, S. algae, S. chilikensis, S. indica, S. xiamenensis, S. seohaensis, and S. carassii. Thus, we can confidently conclude that the MALDI-TOF MS method developed here is capable of identifying Shewanella species.
Although there are over 70 Shewanella species and other species remain to be tested, these six species are the most commonly isolated species from clinical samples, and other species are relatively rare (Zhang et al., 2018). The testing of other 30 Shewanella species included in this database and additional species not included in this study will further expand the utility of this method.

However, in our study, nine out of 125 strains were misidentified. These nine isolates belonged to five species, which were divided into two groups, S. algae-S. chilikensis-S. indica and S. xiamenensis-S. seohaensis. The strains of each group shared the most recent common ancestor in the MLSA phylogenetic tree (Figure 2), suggesting a close evolutionary relationship of the species within each group. The close relatedness is likely to be the cause of the misidentification, as MALDI-TOF MS primarily uses main peaks represented by ribosomal proteins in the spectrum 
A

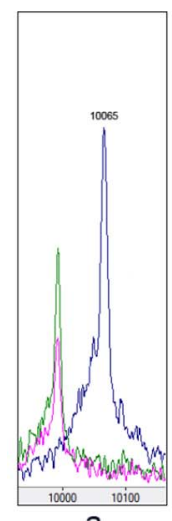

a

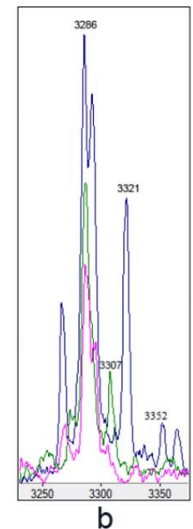

b

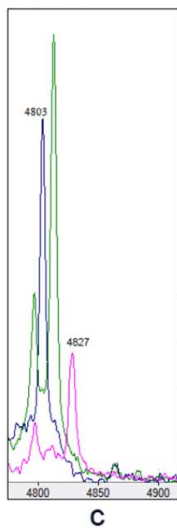

c

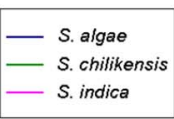

FIGURE 4 | Matrix-assisted laser desorption/ionization time-of-flight mass spectrometry (MALDI-TOF MS) spectra of the five species displayed in the MDT Master: (A) (a) Peak at 10,065 m/z of S. algae compared with S. chilikensis and S. indica; (b) comparison of peak at 3,307 m/z belonging to S. chilikensis to S. algae, S. indica, respectively. (c) Different distribution of peak at 4,827 m/z belonging S. indica compared with $S$. algae and $S$. chilikensis. (B) Different distribution of peaks at $4,221,3,778$, and $9,574 \mathrm{~m} / \mathrm{z}$ between $\mathrm{S}$. xiamenensis and $\mathrm{S}$. seohaensis.

for strain identification (Ryzhov and Fenselau, 2001; Bremer and Dennis, 2008; Nakamura et al., 2016). It is known to be difficult to distinguish by MALDI-TOF MS Shigella spp. from E. coli (Wieser et al., 2012), Brucella melitensis from Ochrobactrum anthropi (Poonawala et al., 2018), and some species within the genus Bacillus (McLaughlin et al., 2014), as there is very little difference between them in the spectra of ribosomal proteins.

In order to overcome the limitations of MALDI-TOF MS in differentiating closely related species, potential species-specific biomarker peaks were found to be useful. Peaks in the range of $2,000-20,000 \mathrm{~m} / z$ are more likely to be ribosomal proteins that are discriminatory at the species level. Ha et al. (2019) successfully applied low-mass profiling to identify species-specific mass peaks for the identification of two genetically closely related Bacillus species. In this study, we took a similar approach and identified species-associated biomarker peaks based on the type strains, validated using the 125 test strains. With the use of the species biomarker peaks, nine misidentified test strains can be accurately identified at the species level. We identified 2-21 species-associated biomarkers for the species level identification. However, it should be noted that these species-associated biomarkers were identified based on one type strain; and thus when more strains of a given species are included, some of these markers may become variable within a species or non-species specific. For the species with multiple test strains available, the species-associated biomarker appears to be species specific.

\section{CONCLUSION}

The establishment of the PMRS library provides the technical basis for the detection and identification of Shewanella species that are relevant to food safety and clinical disease. The study revealed that MALDI-TOF MS could be a fast and relatively inexpensive method for the identification of the Shewanella
B

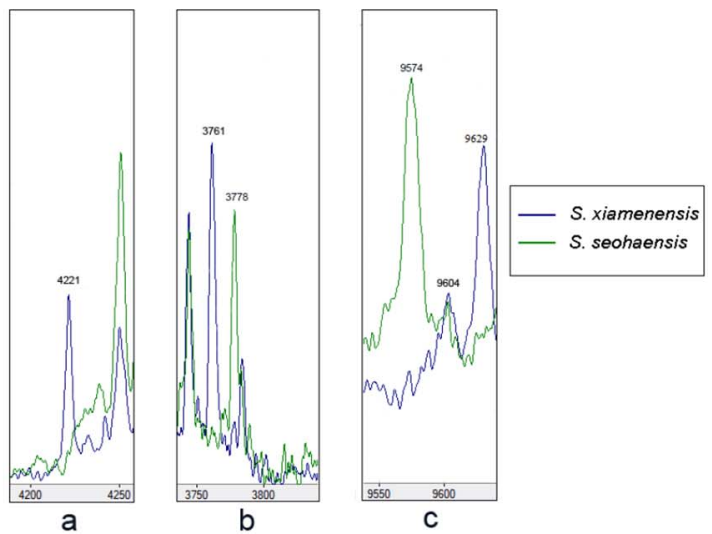

genus. Species-specific biomarker peaks were identified and employed to improve the identifications at the species level. MALDI-TOF MS can effectively replace traditional identification methods for the identification of Shewanella.

\section{DATA AVAILABILITY STATEMENT}

The original contributions presented in the study are included in the article/Supplementary Materials, further inquiries can be directed to the corresponding author/s.

\section{AUTHOR CONTRIBUTIONS}

DW designed the work. $\mathrm{KY}$ and $\mathrm{ZH}$ performed the experiments. $\mathrm{KY}, \mathrm{ZH}, \mathrm{YL}, \mathrm{QF}, \mathrm{LL}, \mathrm{SW}, \mathrm{HD}, \mathrm{HC}$, and YX collected the samples and isolated strains. $\mathrm{KY}, \mathrm{ZH}$, and $\mathrm{RL}$ wrote the manuscript. All authors contributed to the article and approved the submitted version.

\section{FUNDING}

This work was supported by the National Sci-Tech Key Project (2018ZX10102001 and 2018ZX10734404) from the National Health Commission, China and the National Science and Technology Infrastructure of China (National Pathogen Resource Center-NPRC-32).

\section{SUPPLEMENTARY MATERIAL}

The Supplementary Material for this article can be found online at: https://www.frontiersin.org/articles/10.3389/fmicb.2021. 625821/full\#supplementary-material 


\section{REFERENCES}

Angeletti, S. (2017). Matrix assisted laser desorption time of flight mass spectrometry (MALDI-TOF MS) in clinical microbiology. J. Microbiol. Methods 138, 20-29. doi: 10.1016/j.mimet.2016.09.003

Anja, F., and Sascha, S. (2009). Phylogenetic classification and identification of bacteria by mass spectrometry. Nat. Protoc. 4, 732-742. doi: 10.1038/nprot. 2009.37

Bao, J. R., Master, R. N., Azad, K. N., Schwab, D. A., Clark, R. B., Jones, R. S., et al. (2018). Rapid, accurate identification of candida auris by using a novel matrix-assisted laser desorption ionization-time of flight mass spectrometry (MALDI-TOF MS) database (Library). J. Clin. Microbiol. 56, e1700-e1717.

Bozal, N., Montes, M. J., Tudela, E., Jiménez, F., and Guinea, J. (2002). Shewanella frigidimarina and Shewanella livingstonensis sp. nov. isolated from Antarctic coastal areas. Int. J. Syst. Evol. Microbiol. 52, 195-205. doi: 10.1099/0020771352-1- 195

Bremer, H., and Dennis, P. P. (2008). Modulation of chemical composition and other parameters of the cell at different exponential growth rates. EcoSal. Plus 3. doi: 10.1128/ecosal.5.2.3

Byun, J. H., Park, H., and Kim, S. (2017). The phantom menace for patients with hepatobiliary diseases: Shewanella haliotis, often misidentified as Shewanella algae in biochemical tests and MALDI-TOF analysis. Jpn. J. Infect. Dis. 70, 177-180. doi: 10.7883/yoken.jijid.2015.658

Daeffler, K. N., Galley, J. D., Sheth, R. U., Ortiz-Velez, L. C., Bibb, C. O., Shroyer, N. F., et al. (2017). Engineering bacterial thiosulfate and tetrathionate sensors for detecting gut inflammation. Mol. Syst. Biol. 13:923. doi: 10.15252/msb. 20167416

Erfanmanesh, A., Beikzadeh, B., Aziz Mohseni, F., Nikaein, D., and Mohajerfar, T. (2019). Ulcerative dermatitis in barramundi due to coinfection with Streptococcus iniae and Shewanella algae. Dis. Aquat. Organ. 134, 89-97. doi: 10.3354/dao03363

Fang, Y., Wang, Y., Liu, Z., Dai, H., Cai, H., Li, Z., et al. (2019). Multilocus sequence analysis, a rapid and accurate tool for taxonomic classification, evolutionary relationship determination, and population biology studies of the genus Shewanella. Appl. Environ. Microbiol. 85:e3126-18.

Fredrickson, J. K., Romine, M. F., Beliaev, A. S., Auchtung, J. M., Driscoll, M. E., Gardner, T. S., et al. (2008). Towards environmental systems biology of Shewanella. Nat. Rev. Microbiol. 6, 592-603.

Glaeser, S. P., and Kämpfer, P. (2015). Multilocus sequence analysis (MLSA) in prokaryotic taxonomy. Syst. Appl. Microbiol. 38, 237-245. doi: 10.1016/j.syapm. 2015.03.007

Gorby, Y. A., Yanina, S., McLean, J. S., Rosso, K. M., Moyles, D., Dohnalkova, A., et al. (2006). Electrically conductive bacterial nanowires produced by Shewanella oneidensis strain MR-1 and other microorganisms. Proc. Natl. Acad. Sci. U.S.A. 103, 11358-11363. doi: 10.1073/pnas.0604517103

Ha, M., Jo, H. J., Choi, E. K., Kim, Y., Kim, J., and Cho, H. J. (2019). Reliable identification of Bacillus cereus group species using low mass biomarkers by MALDI-TOF MS. J. Microbiol. Biotechnol. 29, 887-896. doi: 10.4014/jmb.1903. 03033

Hau, H. H., and Gralnick, J. A. (2007). Ecology and biotechnology of the genus Shewanella. Annu. Rev. Microbiol. 61, 237-258.

Honnavar, P., Ghosh, A. K., Paul, S., Shankarnarayan, S. A., Singh, P., Dogra, S., et al. (2018). Identification of Malassezia species by MALDI-TOF MS after expansion of database. Diagn. Microbiol. Infect. Dis. 92, 118-123. doi: 10.1016/ j.diagmicrobio.2018.05.015

Janda, J. M., and Abbott, S. L. (2014). The genus Shewanella: from the briny depths below to human pathogen. Crit. Rev. Microbiol. 40, 293-312. doi: 10.3109/ 1040841x.2012.726209

Jang, K. S., and Kim, Y. H. (2018). Rapid and robust MALDI-TOF MS techniques for microbial identification: a brief overview of their diverse applications. J. Microbiol. 56, 209-216. doi: 10.1007/s12275-018-7457-0

Kouzuma, A., Kasai, T., Hirose, A., and Watanabe, K. (2015). Catabolic and regulatory systems in Shewanella oneidensis MR-1 involved in electricity generation in microbial fuel cells. Front. Microbiol. 6:609. doi: 10.3389/fmicb. 2015.00609

Liu, P. Y., Lin, C. F., Tung, K. C., Shyu, C. L., Wu, M. J., Liu, J. W., et al. (2013). Clinical and microbiological features of Shewanella bacteremia in patients with hepatobiliary disease. Intern. Med. 52, 431-438. doi: 10.2169/internalmedicine. 52.8152

McLaughlin, J., Nelson, M., McNevin, D., Roffey, P., and Gahan, M. E. (2014). Characterization of Bacillus strains and hoax agents by protein profiling using automated microfluidic capillary electrophoresis. Forensic. Sci. Med. Pathol. 10, 380-389. doi: 10.1007/s12024-014-9578-z

McLean, J. S., Majors, P. D., Reardon, C. L., Bilskis, C. L., Reed, S. B., Romine, M. F., et al. (2008). Investigations of structure and metabolism within Shewanella oneidensis MR-1 biofilms. J. Microbiol. Methods. 74, 47-56. doi: 10.1016/j. mimet.2008.02.015

Miyazaki, M., Nogi, Y., Usami, R., and Horikoshi, K. (2006). Shewanella surugensis sp. nov., Shewanella kaireitica sp. nov. and Shewanella abyssi sp. nov., isolated from deep-sea sediments of Suruga Bay, Japan. Int. J. Syst. Evol. Microbiol. 56, 1607-1613. doi: 10.1099/ijs.0.64173-0

Nakamura, S., Sato, H., Tanaka, R., and Yaguchi, T. (2016). Verification of ribosomal proteins of Aspergillus fumigatus for use as biomarkers in MALDITOF MS identification. Mass. Spectrom. 5:A0049.

O’Connor, J. A., Lynch-Healy, M., Corcoran, D., O’Reilly, B., O’Mahony, J. and Lucey, B. (2016). improved matrix-assisted laser desorption ionizationtime of flight mass spectrometry (MALDI-TOF MS)-based identification of Mycobacterium spp. by use of a novel two-step cell disruption preparatory technique. J. Clin. Microbiol. 54, 495-496. doi: 10.1128/jcm.02998-15

Pagani, L., Lang, A., Vedovelli, C., Moling, O., Rimenti, G., Pristerà, R., et al. (2003). Soft tissue infection and bacteremia caused by Shewanella putrefaciens. J. Clin. Microbiol. 41, 2240-2241. doi: 10.1128/jcm.41.5.2240-2241.2003

Paul, S., Singh, P., Sharma, S., Prasad, G. S., Rudramurthy, S. M., Chakrabarti, A., et al. (2019). MALDI-TOF MS-based identification of Melanized Fungi is faster and reliable after the expansion of in-house database. Proteomics Clin. Appl. 13:e1800070.

Poonawala, H., Marrs Conner, T., and Peaper, D. R. (2018). Closing the brief case: misidentification of brucella melitensis as Ochrobactrum anthropi by matrix-assisted laser desorption ionization-time of flight mass spectrometry (MALDI-TOF MS). J. Clin. Microbiol. 56:e00918-17.

Regoui, S., Hennebique, A., Girard, T., Boisset, S., Caspar, Y., and Maurin, M. (2020). Optimized MALDI TOF mass spectrometry identification of Francisella tularensis Subsp. holarctica. Microorganisms 8:1143. doi: 10.3390/ microorganisms 8081143

Rodriguez-Temporal, D., Perez-Risco, D., Struzka, E. A., Mas, M., and Alcaide, F. (2017). Impact of updating the MALDI-TOF MS database on the identification of nontuberculous mycobacteria. J. Mass Spectrom. 52, 597-602. doi: 10.1002/ jms.3944

Ryzhov, V., and Fenselau, C. (2001). Characterization of the protein subset desorbed by MALDI from whole bacterial cells. Anal. Chem. 73, 746-750. doi: 10.1021/ac0008791

Samantha, S., Daniel, K., Robin, P., and Audrey, N. S. (2018). Routine use of MALDI-TOF MS for anaerobic bacterial identification in clinical microbiology. Anaerobe 54, 191-196. doi: 10.1016/j.anaerobe.2018.07.001

Sánchez-Juanes, F., Teixeira-Martín, V., González-Buitrago, J. M., Velázquez, E., and Flores-Félix, J. D. (2020). Identification of species and subspecies of lactic acid bacteria present in spanish cheeses type "Torta" by MALDITOF MS and pheS gene Analyses. Microorganisms 8:301. doi: 10.3390/ microorganisms 8020301

Schubert, S., and Kostrzewa, M. (2017). MALDI-TOF MS in the microbiology laboratory: current trends. Curr. Issues. Mol. Biol. 23, 17-20. doi: 10.21775/ cimb.023.017

Sun, D. L., Jiang, X., Wu, Q. L., and Zhou, N. Y. (2013). Intragenomic heterogeneity of 16S rRNA genes causes overestimation of prokaryotic diversity. Appl. Environ. Microbiol. 79, 5962-5969. doi: 10.1128/aem.01282-13

Sung, H. R., Yoon, J. H., and Ghim, S. Y. (2012). Shewanella dokdonensis sp. nov., isolated from seawater. Int. J. Syst. Evol. Microbiol. 62, 1636-1643. doi: 10.1099/ijs.0.032995-0

van Belkum, A., Chatellier, S., Girard, V., Pincus, D., Deol, P., Dunne, W. M. Jr., et al. (2015). Progress in proteomics for clinical microbiology: MALDI-TOF MS for microbial species identification and more. Expert. Rev. Proteomics 12, 595-605. doi: 10.1586/14789450.2015.1091731

Wang, F., Xiao, X., Ou, H. Y., Gai, Y., and Wang, F. (2009). Role and regulation of fatty acid biosynthesis in the response of Shewanella piezotolerans WP3 to 
different temperatures and pressures. J. Bacteriol. 191, 2574-2584. doi: 10.1128/ jb.00498-08

Wieser, A., Schneider, L., Jung, J., and Schubert, S. (2012). MALDI-TOF MS in microbiological diagnostics-identification of microorganisms and beyond (mini review). Appl. Microbiol. Biotechnol. 93, 965-974. doi: 10.1007/s00253011-3783-4

Yarza, P., Yilmaz, P., Pruesse, E., Glöckner, F. O., Ludwig, W., Schleifer, K. H., et al. (2014). Uniting the classification of cultured and uncultured bacteria and archaea using 16S rRNA gene sequences. Nat. Rev. Microbiol. 12, 635-645. doi: $10.1038 /$ nrmicro3330

Yousfi, K., Bekal, S., Usongo, V., and Touati, A. (2017). Current trends of human infections and antibiotic resistance of the genus Shewanella. Eur. J. Clin. Microbiol. Infect. Dis. 36, 1353-1362. doi: 10.1007/s10096-0172962-3

Zhang, F., Fang, Y., Pang, F., Liang, S., Lu, X., Kan, B., et al. (2018). Rare Shewanella spp. associated with pulmonary and bloodstream infections of cancer patients, China: a case report. BMC Infect. Dis. 18:454. doi: 10.1186/s12879-0183354-8
Zou, L., Huang, Y. H., Long, Z. E., and Qiao, Y. (2018). On-going applications of Shewanella species in microbial electrochemical system for bioenergy, bioremediation and biosensing. World. J. Microbiol. Biotechnol. 35:9.

Conflict of Interest: QF, LL, and SW were employed by the company Zybio Inc. Chongqing, China.

The remaining authors declare that the research was conducted in the absence of any commercial or financial relationships that could be construed as a potential conflict of interest.

Copyright (c) 2021 Yu, Huang, Li, Fu, Lin, Wu, Dai, Cai, Xiao, Lan and Wang. This is an open-access article distributed under the terms of the Creative Commons Attribution License (CC BY). The use, distribution or reproduction in other forums is permitted, provided the original author(s) and the copyright owner(s) are credited and that the original publication in this journal is cited, in accordance with accepted academic practice. No use, distribution or reproduction is permitted which does not comply with these terms. 